\title{
Impact Properties of Aluminium - Glass Fiber Reinforced Plastics Sandwich Panels
}

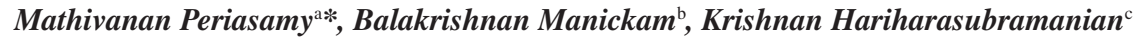 \\ a Department of Mechanical Engineering, Valliammai Engineering College, \\ Tamil Nadu State, 603203, India \\ ${ }^{\mathrm{b}}$ Department of Aerospace Engineering, SRM University, Tamil Nadu State, 603203, India \\ 'Department of Physics, Valliammai Engineering College, Tamil Nadu State, 603203, India
}

Received: March 25, 2010; Revised: February 7, 2012

\begin{abstract}
Aluminium - glass fiber reinforced plastics (GFRP) sandwich panels are hybrid laminates consisting of GFRP bonded with thin aluminum sheets on either side. Such sandwich materials are increasingly used in airplane and automobile structures. Laminates with varying aluminium thickness fractions, fiber volume fractions and orientation in the layers of GFRP were fabricated by hand lay up method and evaluated for their impact performance by conducting drop weight tests under low velocity impacts. The impact energy required for initiating a crack in the outer aluminium layer as well as the energy required for perforation was recorded. The impact load-time history was also recorded to understand the failure behavior. The damage depth and the damage area were measured to evaluate the impact resistance. Optical photography and scanning electron micrographs were taken to visualize the crack and the damage zone. The bidirectional cross-ply hybrid laminate (CPHL) has been found to exhibit better impact performance and damage resistance than the unidirectional hybrid laminate (UDHL). Increase in aluminium thickness fraction $\left(\mathrm{Al}_{\mathrm{tf}}\right)$ and fiber volume fraction $\left(\mathrm{V}_{\mathrm{f}}\right)$ resulted in an increase in the impact energy required for cracking and perforation. On an overall basis, the sandwich panels exhibited better impact performance than the monolithic aluminium.
\end{abstract}

Keywords: aluminium - glass fiber sandwich panels, impact performance, impact resistance

\section{Introduction}

Aluminium - glass fiber sandwich panels are hybrid laminates in which aluminium alloy sheets are bonded to glass fiber reinforced plastics (GFRP) layers. Such laminates combine the good properties of both the materials. However, the moderate to poor ones are also combined ${ }^{1}$. Good characteristics of aluminium such as ductility, specific stiffness, and impact and damage tolerances together with the benefits of fiber composite materials such as high specific strength, good corrosion and fatigue resistances are obtained. These hybrid laminates are used to substitute monolithic aluminium resulting in weight savings without much compromise to the strength to weight ratio. In particular, these sandwich materials find application in tension dominated structural components and where a small savings in weight could lead to a large savings in fuel cost as in aerospace and automobile structures ${ }^{2}$. These materials can be used where a glossy fine metallic surface finish is required as in automobiles.

The lay up of aluminium - glass fiber reinforced plastics sandwich panel is shown in Figure 1. There may be any number of aluminium and FRP layers but the ratio between the number of aluminium and FRP layers should be $(n+1) / n$ where $n$ is the number of FRP layers ${ }^{3}$ so that the outermost layer is always aluminium on both sides. Earlier research works on such hybrid laminates have demonstrated that these laminates are superior to composite or monolithic

*e-mail: permathi61@yahoo.co.in aluminium. M. Kawai et al. ${ }^{4}$ studied the off-axis inelastic and fracture behavior of Aluminium-GFRP hybrid laminates under static tensile loading conditions. They have found that the tensile fracture strength is almost two times as large as that of the monolithic aluminium alloy in the fiber direction, and it is about five times the value of the GRP layers in the transverse direction.

T. J. De Vries and A. Vlot ${ }^{5}$ studied the influence of the constituent properties on the residual strength of aluminium alloy-Glass fiber reinforced hybrid material. They have developed an experimental program and performed it on hybrid laminates built up from several combinations of aluminium alloys and fibers. They also studied the fracture mechanism. They found that a larger strain hardening region and a lower yield stress of the aluminium layers has a positive influence on the residual strength due to the capability of transferring high loads away from the cracked area.

B. Borgonje et al. ${ }^{6}$ investigated the long term behavior of aluminium-glass fiber epoxy laminates. They have shown that the performance of hybrid laminates is better when compared to monolithic aluminium with respect to corrosion. The use of glass fibers in the GFRP layer prevents any galvanic corrosion because glass fibers are electric insulators. Debonding due to corrosion is absent as no clad layer was used in the hybrid laminate. They also found that thin aluminium alloy sheets used in the hybrid 


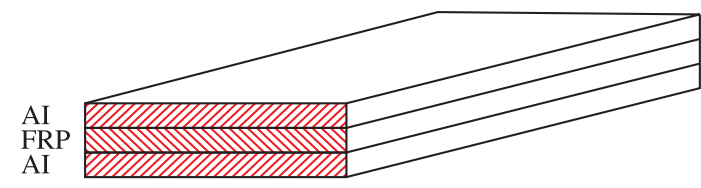

Figure 1. Aluminium-GFRP sandwich panel.

laminates showed better corrosion resistance than the sheets of conventional thickness. The fatigue behavior, corrosion and flame resistance of hybrid Aluminium-Glass fiber laminates have been evaluated by L. B. Vogelesang and A. Vlot ${ }^{1}$. They reported that the hybrid laminates have better fatigue resistance, corrosion resistance and flame resistance than monolithic aluminium alloy. G. Reyes and H. Kang ${ }^{7}$ investigated the mechanical behavior of thermoplastic glass fiber reinforced polypropylene composite and aluminium alloy hybrid laminates. They found that these laminates showed excellent forming properties similar to that of monolithic aluminium alloy of comparable thickness.

One of the important safety issues concerned with these hybrid laminates is the impact performance/resistance. This is because, when such hybrid laminates are used in aerospace/automobile structures, they frequently experience damages due to impact sources like dropped tools during maintenance, runway debris, collisions between service cars or cargos and the structure, hails and bird hits, tyre shrapnel from tread separation and tyre ruptures ${ }^{8}$. Parameters that control the impact properties of this hybrid system are the thickness of layers, fiber volume fraction, constituent materials of FRP, fiber orientation, bonding material, and impact velocity/energy.

A. Vlot $^{9}$ performed low and high velocity impact on aluminium - glass fiber epoxy laminates, aluminiumaramid fiber epoxy laminates and aluminium - carbon fiber epoxy laminates. He has shown that the energy required to create the first crack in the outer aluminium layer on the non impacted side was more in case of hybrid laminates with glass fiber than that of carbon and aramid fibers. The glass fiber hybrid laminate was found to exhibit a fiber or aluminium critical failure mode. The dent depth of the hybrid laminate was found to be more or less equal to that of monolithic aluminium alloy and the damage area after impact was found to be considerably lower than plain GFRP/ CFRP laminates. The tensile strength of aluminium glass fiber hybrid laminates increased with increasing strain rate due to strain rate dependent behavior of glass fiber.

The fiber matrix adhesion and its effects on the impact behavior of carbon fiber reinforced aluminium laminates was studied by G. D. Lawcock et al. ${ }^{10}$. They performed quasi static, low hanging and high velocity impact tests. They found that laminates with weaker fiber/matrix adhesion had larger damage zones even though the back face crack length and permanent indentation after impact were smaller for a given impact energy. Residual tensile strength after impact was found to be higher for the untreated fiber laminates due to increase in fiber/matrix splitting in the composite layer. S. H. Song et al. ${ }^{11}$ investigated about the impact performance of carbon reinforced aluminium hybrid laminates, both experimentally and numerically. They observed that the specimen impacted by $2.35 \mathrm{~J}$ energy showed no critical damage and also absorbed $64 \%$ of the impact energy and that the specimen impacted by $9.40 \mathrm{~J}$ showed fiber and matrix failures in CFRP layers and a shear crack on the aluminium layer with absorption of $83 \%$ of the impact energy. Thus they found that the specimen impacted by $2.35 \mathrm{~J}$ showed less failure mechanism.

F. Ashenai Ghasemi et al. ${ }^{12}$ studied about the impact performance of Aluminium/Steel and Glass/Carbon fiber epoxy hybrid laminates under low velocity impact. They found that factors such as layer sequence of metal layers, material type of metal layers and composite medium, the $\mathrm{E}_{11} / \mathrm{E}_{22}$ ratio of composite medium were very significant in affecting the dynamic behavior of the impacted laminates. G. S. Langdon and L. A. Rowe ${ }^{13}$ carried out blast loading tests on Steel/Aluminium alloy-GFRP hybrid laminates. They showed that the blast loaded laminates exhibited large inelastic deformation and debonding failure of the steel-composite interface similar to that of AluminiumGFRP panels. They also found that the non dimensional displacement of Steel-GFRP panels were lower than that of Aluminium-GFRP panels.

S. Mckown et al. ${ }^{14}$ investigated on the scaling effects of Aluminium alloy-polypropylene hybrid laminates. They found that the laminates no significant scaling effects with respect to the tensile and flexural properties but the impact force and damage threshold energy obeyed scaling law.

Although many studies have been carried out on hybrid metal fiber laminates, published information is very limited on the influence of thickness of metal layers, type of fibers and matrix materials used, fiber volume fraction, fiber orientation, adhesives for bonding the fiber composite with the metal layer and the impact velocity/energy on the impact properties. In this paper, a study and discussion on the influence of metal thickness, fiber volume fraction and fiber orientation on the impact properties of the sandwich hybrid laminates has been presented which will lead to a better understanding of the behavior of the sandwich hybrid laminates under impact loading situations. The failure pattern under such conditions can give valuable information which could in turn be used for designing new laminates.

\section{Experimental}

\subsection{Specimen preparation}

The materials used in the fabrication of the test specimens were:

1. Aluminium alloy sheets - AA 1050 H 14;

2. E-glass fibers reinforced in epoxy resin (LY 556) matrix;

3. Epoxy resin as adhesive.

The properties of the constituent materials are given in Table 1. Square specimens of size $90 \times 90 \mathrm{~mm}$ were made by varying the thickness of the aluminium sheets while keeping the thickness of FRP layer constant (Table 2). The Aluminium thickness fraction is defined as the ratio between the aluminium thickness and the total thickness of the hybrid laminate. Aluminium alloy sheet (Grade AA 1050 H 14 supplied by HINDALCO) was uniformly roughened on one 
Table 1. Material properties.

\begin{tabular}{cccccc}
\hline S.N $^{\circ}$ & Material & $\begin{array}{c}\text { Elastic } \\
\text { modulus } \\
(\mathbf{G P a})\end{array}$ & $\begin{array}{c}\text { Yield } \\
\text { strength } \\
(\mathbf{M P a})\end{array}$ & $\begin{array}{c}\text { Ultimate } \\
\text { strength } \\
(\mathbf{M P a})\end{array}$ & $\begin{array}{c}\text { Specific } \\
\text { weight } \\
\left(\mathbf{k g . m}^{-3}\right)\end{array}$ \\
\hline 1 & Aluminium & 68 & 120 & 145 & 2700 \\
2 & E-Glass Fiber & 72 & & 3450 & 2540 \\
3 & Epoxy & 3.5 & & 95 & 1100 \\
\hline
\end{tabular}

Table 2. Thickness of aluminum and FRP layers.

\begin{tabular}{ccccc}
\hline S.N $^{\circ}$ & $\begin{array}{c}\text { Aluminium } \\
\text { thickness fraction }\end{array}$ & $\begin{array}{c}\text { Aluminium } \\
(\mathbf{m m})\end{array}$ & $\begin{array}{c}\text { FRP } \\
(\mathbf{m m})\end{array}$ & $\begin{array}{c}\text { Total thickness } \\
(\mathbf{m m})\end{array}$ \\
\hline 1 & 0.4516 & $0.7+0.7$ & 1.7 & 3.1 \\
2 & 0.3703 & $0.5+0.5$ & 1.7 & 2.7 \\
\hline
\end{tabular}

side so as to get good bonding with the epoxy resin. An acrylic mould as per the specimen shape was made. The surfaces of the aluminium were wiped and cleaned using acetone. Chopped strand mats (CSM) made of E - glass fiber were cut to the sample shape. Epoxy resin LY 556 and hardener Aradur HY 951 supplied by HUNTSMAN were mixed in the ratio 100 parts to 10 parts by weight respectively.

The surface of the aluminum sheet and the inner surface of the mould cavity were coated with wax. The aluminium sheet was placed inside the mould with the roughened surface facing up. A coating of the resin-hardener mixture was applied over the aluminium surface followed by placing the CSM over the above coating. Two layers of unidirectional (UD) fibers wetted with resin hardener mixture were then placed over the CSM. A CSM layer was again placed over which the outer aluminium sheet was placed. The mould cavity was closed by a wax coated acrylic sheet. Weights were placed over the sheet in such a way that uniform pressure was obtained. The set up was left for curing for 6 hours at room temperature. Specimens were prepared with different aluminium thickness, fiber volume fractions $(24,30$ and $35 \%)$ and fiber orientations (unidirectional and bidirectional). Plain aluminium specimens of thickness $2 \mathrm{~mm}$ and dimensions $90 \times 90 \mathrm{~mm}$ were also tested for their impact performance at room temperature.

\subsection{Evaluation of impact properties}

The number of specimens tested for each type of hybrid laminate (that is for each aluminium thickness fraction and fiber volume fraction and orientation) is 3 and for each testing condition (cracking, perforation etc) is also 3. All the specimens were tested in an instrumented drop weight impact testing machine (FRACTOVICS PLUS make) under low velocity $(<11 \mathrm{~m} / \mathrm{s})^{9,15}$. The specimens were clamped in a fixture between two steel plates with a circular central opening of $76 \times 76 \mathrm{~mm}$. The steel indenter used to impact the specimens was of spherical shape with $12.7 \mathrm{~mm}$ diameter. The total impactor mass was $4.91 \mathrm{~kg}$. The specimens were impacted at various impact energies by adjusting the drop height of the impactor. The velocity of impact was kept between 3.5 to $4.5 \mathrm{~m} / \mathrm{s}$. The pneumatic actuator in the machine prevents the indenter from multiple strikes due to rebounding after the first impact.

The impact energies were selected such that the impact damage was varied from light plastic indentation on the aluminum layer up to complete perforation of the whole hybrid laminate. The specimens were carefully removed from the fixture after testing for taking optical photographs and scanning electron micrographs of the damage area. The impact force-time history was also recorded during the testing. The minimum cracking energy is the impact energy at which a visible crack appears on the outer aluminium surface on the non impacted side of the sandwich laminate. The perforation energy is the impact energy at which a through crack/complete piercing results in the sandwich laminate. The impact damage resistance is quantified by the above two energy values together with the damage depth and the damage area.

\section{Results and Discussion}

\subsection{Effect of fiber volume fraction on the impact performance}

Impact properties of unidirectional aluminium - glass fiber laminate specimens (UDHL) of different fiber volume fraction and under various impact energies are given in Table 3 (mean value). The impact energy has been varied from plastic denting of the outer aluminium layer up to perforation of the whole specimen. The specific minimum cracking energy and the specific perforation energy are obtained by dividing the energy values by the areal density of the specimen ${ }^{15}$. The specific cracking energy and the specific perforation energy for the hybrid laminates is of the order of 2.4 and $6.3 \mathrm{~J} \cdot \mathrm{m}^{2} \cdot \mathrm{kg}^{-1}$. A. Vlot ${ }^{9}$ has reported a specific cracking and specific perforation energy at 6.47 and $8.8 \mathrm{~J} . \mathrm{m}^{2} \cdot \mathrm{kg}^{-1}$ for hybrid aluminium-R glass fiber epoxy laminates. The specific energy values as reported by A.Vlot is higher because the areal density of the hybrid laminate specimens was $3.4 \mathrm{~kg} \cdot \mathrm{m}^{-2}$ whereas the areal density of the hybrid laminates is about $6 \mathrm{~kg} \cdot \mathrm{m}^{-2}$ in the present investigation and also due to use of $\mathrm{R}$ glass fibers in the GFRP layers by A.Vlot as against E glass fibers used in the present research.

The strain energy during impact is stored mainly by the fibers in the FRP layer of the hybrid laminate and the contribution from the epoxy matrix layer is negligible particularly during the pre initial fracture. The fiber strain energy $U_{f}$ is related ${ }^{16}$ to fiber volume fraction $V_{f}$ as

$$
U_{f}=\sigma_{f}^{2} \times V_{f} / 6 E_{f}
$$

where,

- $\sigma_{\mathrm{f}}=$ longitudinal stress at the outermost layers

- $\mathrm{E}_{\mathrm{f}}=$ fiber modulus

- $\mathrm{V}_{\mathrm{f}}=$ fiber volume fraction

This equation indicates that the energy in the pre initial impact region could be increased by increasing the fiber volume fraction. Hence the hybrid laminate exhibits an increase in the energy required to initiate a crack in the outer aluminium layer as the impact force is transmitted to the FRP layer first and then to the outer aluminium layer. For similar 
Table 3. Specific characterization impact energies for hybrid laminates.

\begin{tabular}{|c|c|c|c|c|c|c|c|c|}
\hline S. No & Material & $\mathbf{A l}_{\mathrm{tf}}$ & $V_{f}(\%)$ & $\begin{array}{l}\text { Areal density } \\
\quad\left(\mathrm{kg} \cdot \mathrm{m}^{-2}\right)\end{array}$ & $\begin{array}{l}\text { Min. cracking } \\
\text { energy }(\mathbf{J})\end{array}$ & $\begin{array}{c}\text { Min. perforation } \\
\text { energy }(J)\end{array}$ & $\begin{array}{c}\text { Sp.cracking } \\
\text { energy }\left(\mathrm{J} . \mathrm{m}^{2} \cdot \mathrm{kg}^{-1}\right)\end{array}$ & $\begin{array}{c}\text { Sp. perf. energy } \\
\left(\mathrm{J} \cdot \mathrm{m}^{2} \cdot \mathrm{kg}^{-1}\right)\end{array}$ \\
\hline 1 & UDHL & 0.4516 & 24 & 6.23 & 14.53 & 40.72 & 2.33 & 6.53 \\
\hline 2 & UDHL & 0.4516 & 30 & 6.38 & 15.38 & 43.66 & 2.41 & 6.84 \\
\hline 3 & UDHL & 0.4516 & 35 & 6.51 & 16.40 & 46.80 & 2.52 & 7.19 \\
\hline 4 & UDHL & 0.3703 & 24 & 5.15 & 10.78 & 29.90 & 2.09 & 5.80 \\
\hline 5 & UDHL & 0.3703 & 30 & 5.30 & 11.61 & 32.03 & 2.19 & 6.04 \\
\hline 6 & UDHL & 0.3703 & 35 & 5.43 & 12.40 & 34.60 & 2.28 & 6.38 \\
\hline 7 & CPHL & 0.4516 & 35 & 6.54 & 19.50 & 49.70 & 2.98 & 7.60 \\
\hline 8 & Aluminium & - & - & 5.40 & 12.60 & 31.42 & 2.33 & 5.82 \\
\hline
\end{tabular}

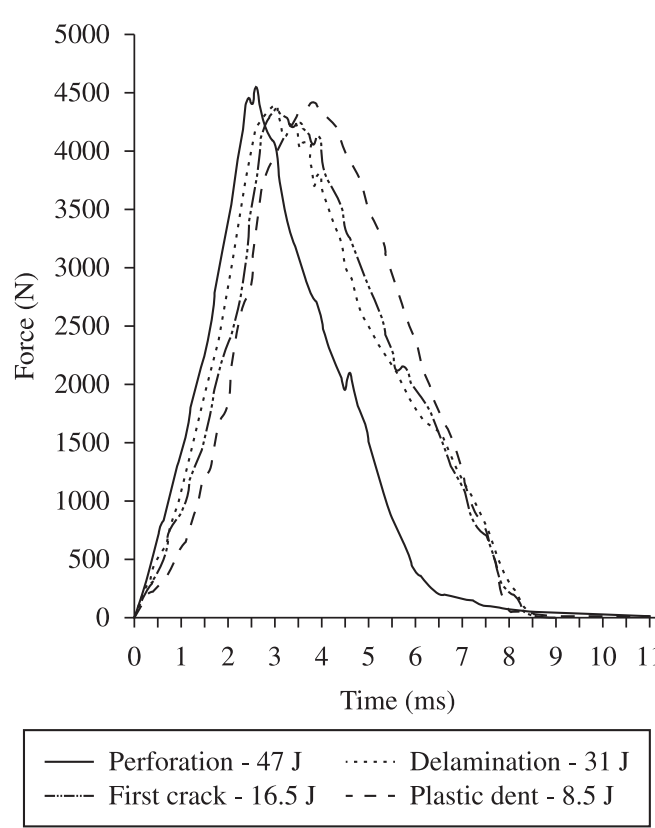

Figure 2. Impact force-time history of UDHL.

reasons, the minimum energy required for perforation is also increased with increase in fiber volume fraction. It can be observed from the results that the extent of increase in specific perforation energy (up to 5.5\%) is greater than that of the specific energy for crack formation (up to $4.5 \%$ ) as the fiber volume fraction is increased. This indicates that hybrid laminates with higher fiber volume fraction perform better during impact conditions that cause perforation.

\subsection{Effect of aluminium thickness fraction on the impact performance}

UDHL specimens with two different $\mathrm{Al}_{\mathrm{tf}}(0.4516$ and 0.3703 ) have been tested for their impact performance and the results are given in Table 3 . It is seen that as the $\mathrm{Al}_{\mathrm{tf}}$ increases both the specific energy required for cracking and that for perforation increases for a constant fiber volume fraction. Aluminium, being ductile in nature, yields

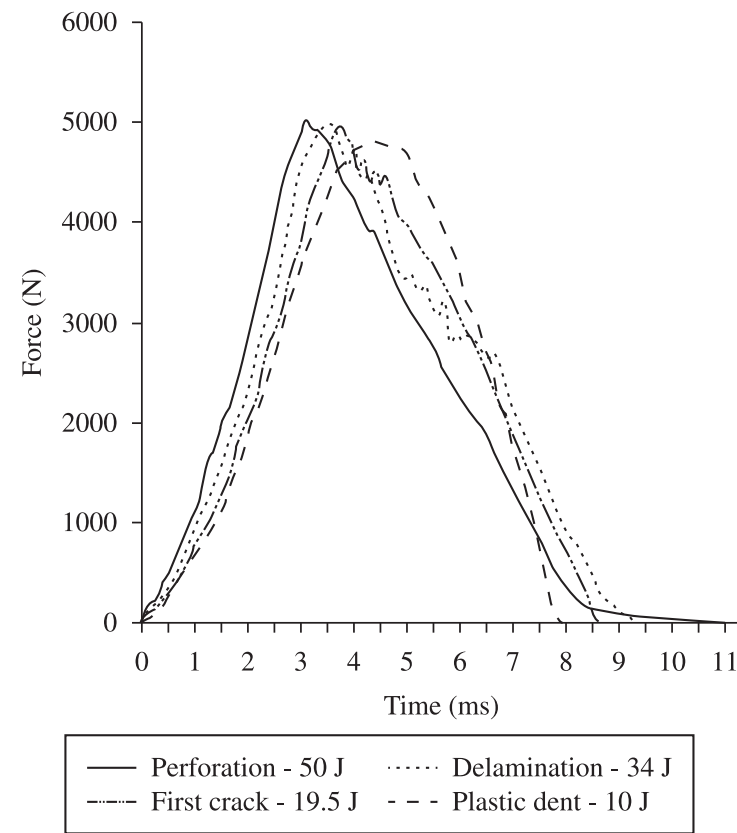

Figure 3. Impact force-time history of CPHL.

considerably before fracture. Hence, an increase in the thickness of aluminium layer $\left(\mathrm{Al}_{\mathrm{tf}}\right)$ increases the impact energy required for initiating as well as propagating the fracture.

\subsection{Effect of fiber orientation in the layers of FRP on the impact performance}

Specimens of unidirectional and bidirectional fibers in the FRP layers of the sandwich laminate have been impact tested and it is observed that the specific energy required for first cracking and perforation is higher for CPHL than UDHL. This is because the impact force by the spherical steel indenter is more uniformly distributed in the bidirectional laminate than the unidirectional laminate.

The impact force-time history for both UDHL and CPHL are shown in Figures 2 and 3 respectively. A permanent plastic indentation occurs at the aluminium layer 
of the UDHL at impact energy of 8.5 J. However, an impact energy of about $10 \mathrm{~J}$ is required to create plastic indentation for CPHL having the same $\mathrm{Al}_{\text {tf }}$ and $\mathrm{V}_{\mathrm{f}}$ which indicates that CPHL has higher denting resistance than UDHL. Table 4 shows the impact energy required to produce a particular type of damage for UDHL and CPHL. The smooth forcetime history curve for both UDHL and CPHL (Figures 2 and 3) indicate that only plastic indentation has occurred. Furthermore, optical photograph of the sectioned specimen at the mid plane (Figure 4) shows that debonding of the aluminium layer on the non impacted side as well as GFRP fracture has started. This may be because of the bending deformation of the laminate due to impact load giving rise

Table 4. Damage types for various impact energies.

\begin{tabular}{cccc}
\hline S.N $^{\mathbf{0}}$ & Description & UDHL & CPHL \\
\hline 1 & $\mathrm{Al}_{\mathrm{tf}}$ & 0.4516 & 0.4516 \\
2 & $\mathrm{~V}_{\mathrm{f}}$ & $35 \%$ & $35 \%$ \\
3 & Areal density $\left(\mathrm{kg} \cdot \mathrm{m}^{-2}\right)$ & 6.51 & 6.54 \\
4 & Plastic denting & $8.5 \mathrm{~J}$ & $10 \mathrm{~J}$ \\
5 & First cracking & $16.4 \mathrm{~J}$ & $19.5 \mathrm{~J}$ \\
6 & Delamination/Fracture & $31.4 \mathrm{~J}$ & $34.6 \mathrm{~J}$ \\
7 & Perforation & $46.8 \mathrm{~J}$ & $49.7 \mathrm{~J}$ \\
8 & Sp. cracking Energy $\left(\mathrm{J} \cdot \mathrm{m}^{2} \cdot \mathrm{kg}^{-1}\right)$ & 2.52 & 2.98 \\
9 & Sp. perforation energy $\left(\mathrm{J}^{2} \mathrm{~m}^{2} \cdot \mathrm{kg}^{-1}\right)$ & 7.19 & 7.60 \\
\hline
\end{tabular}

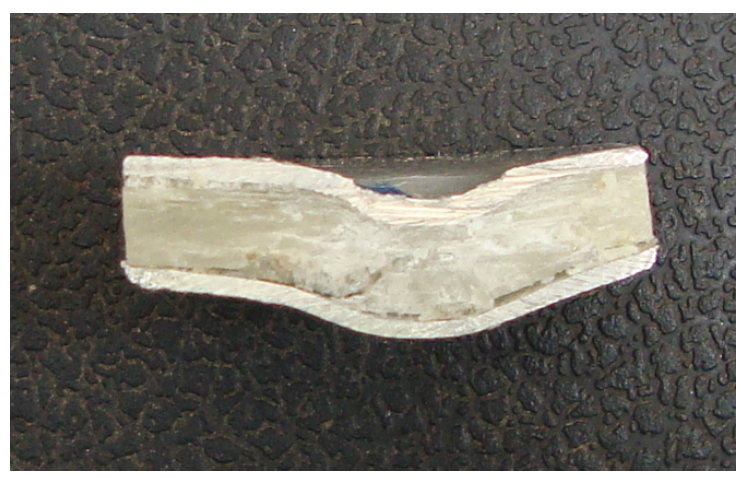

Figure 4. Photograph showing debonding of outer Al.layer in UDHL $(8.5 \mathrm{~J})$.

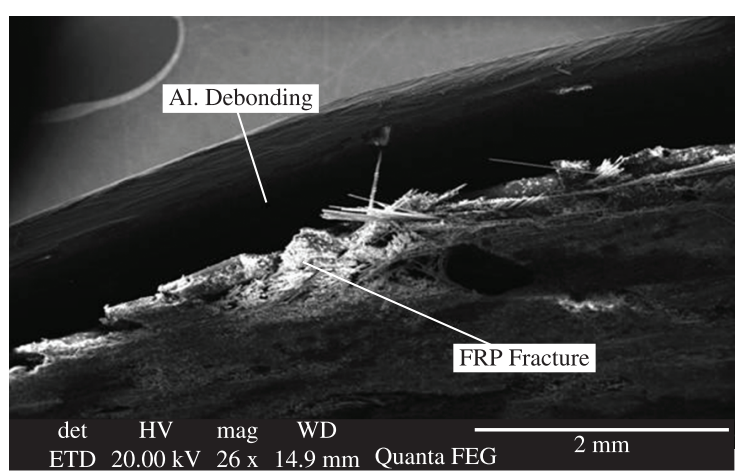

Figure 5. Debonding of Al layer and fracture of GFRP layer in UDHL ( $8.5 \mathrm{~J})$. to interfacial shear stress. This stress causes debonding between aluminium and composite layers. Scanning electron micrograph in Figure 5 shows debonding of aluminium layer and cracking in the GFRP layer.

When the impact energy is increased to $16.5 \mathrm{~J}$, crack appears on the non impacted side of the outer aluminium layer of the UDHL. This is shown as a sharp load drop in the impact force time curve for both types of hybrid laminates. It is observed that a small crack is initiated in the transverse direction in the CPHL in addition to the crack along the $0^{\circ}$ direction. It is also found that the crack direction in the UDHL is along the $0^{\circ}$ fiber orientation and only at a higher impact energy crack appears on the transverse direction. This is shown in the optical photograph of the laminates in Figures 6 and 7. Optical photograph of the sectioned specimen at the mid plane of impact shown in Figure 8 also confirms this observation. SEM micrograph (Figure 9) shows the longitudinal as well as transverse crack in the CPHL. Necking of aluminium layer is also seen at the time of cracking. For CPHL crack initiation energy is $19.5 \mathrm{~J}$ which implies that CPHL has higher first cracking energy than UDHL.

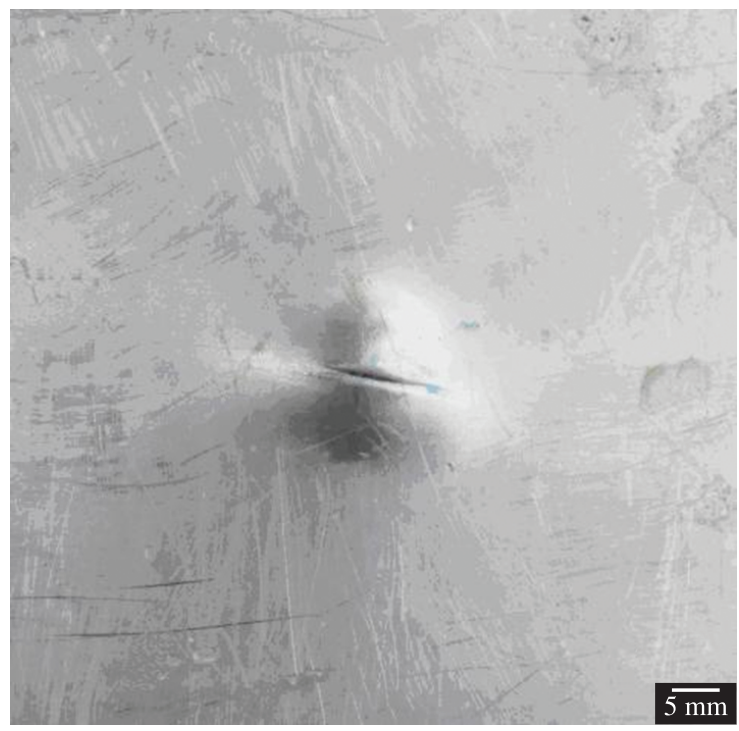

Figure 6. Crack initiation direction in UDHL.

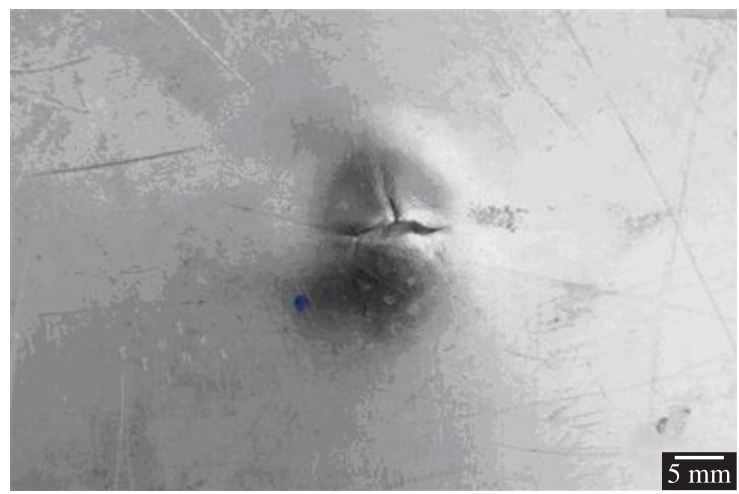

Figure 7. Crack initiation directions in CPHL. 


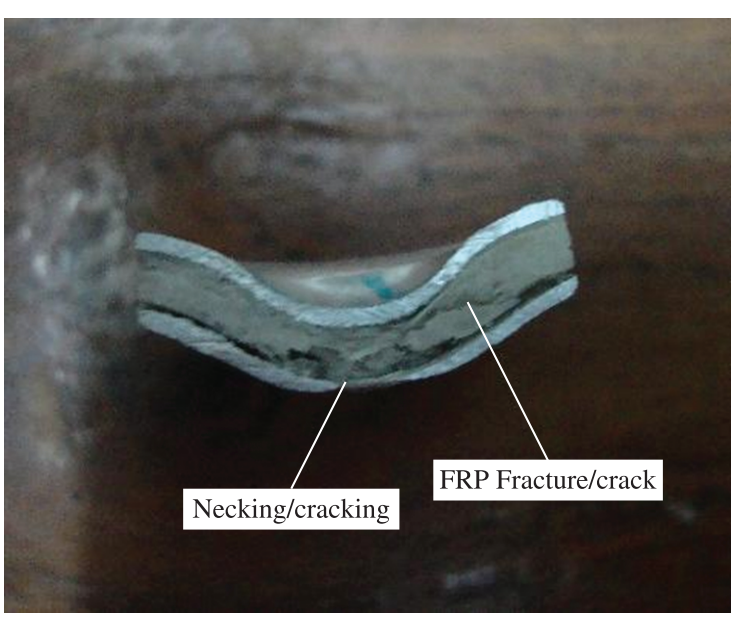

Figure 8. Necking and cracking of Al. layer and cracking in GFRP layer in UDHL (16.5 J).

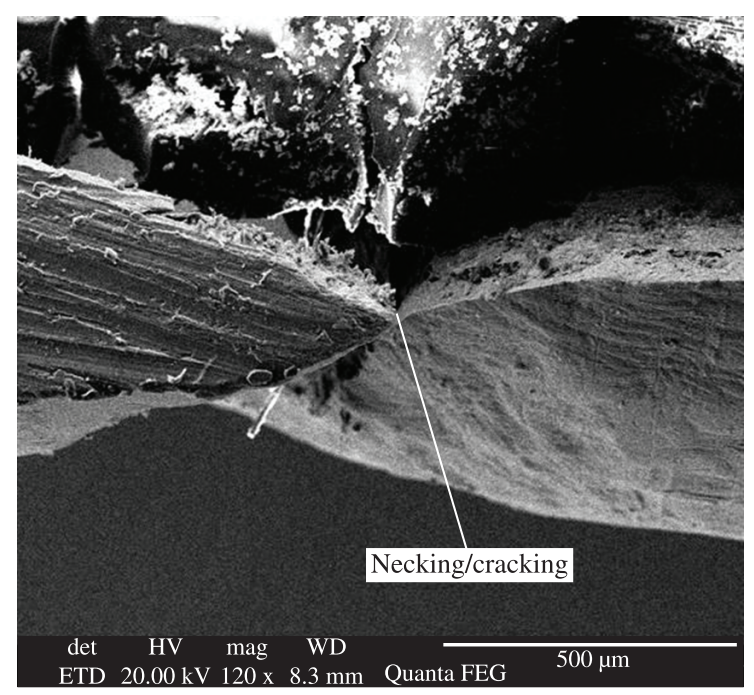

Figure 9. Necking and cracking of outer aluminium layer in CPHL at I.E. of $19.5 \mathrm{~J}$ (Longitudinal and transverse).

When the impact energy is about $31 \mathrm{~J}$, discrete load drops are observed for the UDHL following the sharp load drop due to initiation of crack. These load drops could be attributed to delamination as well as failure of FRP layers due to fiber breakage and matrix cracking. Micrograph of the specimen (Figure 10) shows that due to increased impact energy the damage has become severe and a combination of extensive fiber breakage and matrix cracks and delamination of the layers have taken place.

For CPHL such failure occurs at higher impact energy of $34 \mathrm{~J}$. The load drops in the CPHL is more pronounced than the load drops in UDHL. This is due to the uniform failure of fibers at both $0^{\circ}$ and $90^{\circ}$ in the CPHL than the failure of $0^{\circ}$ fiber in the UDHL. Finally at an impact energy of $47 \mathrm{~J}$ for the UDHL and at about $50 \mathrm{~J}$ for the CPHL, the aluminium layer at the impacted side also gets cracked and consequently the laminates are perforated by means of a through crack formation. From Table 4, it is observed that the impact energy

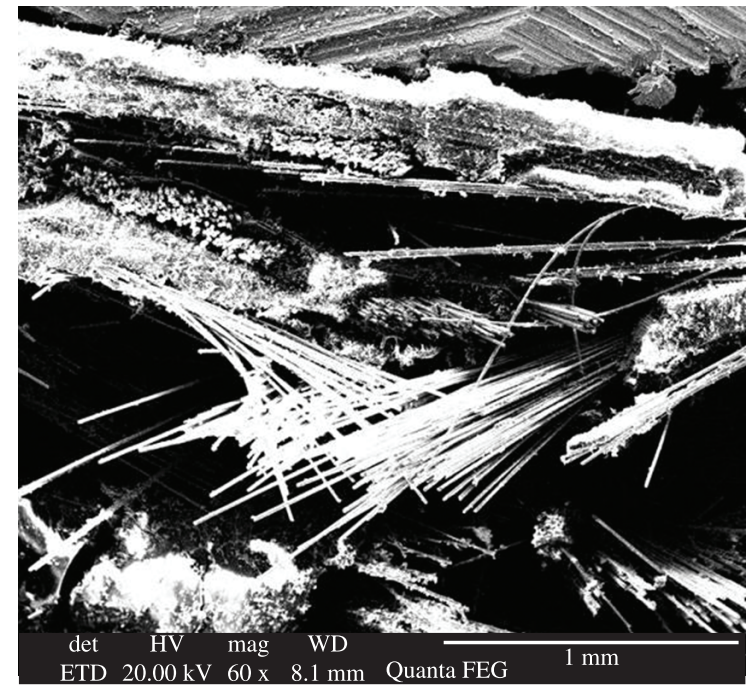

Figure 10. Extensive fiber breakage and matrix cracking at increased I.E. of $31 \mathrm{~J}$ in UDHL.

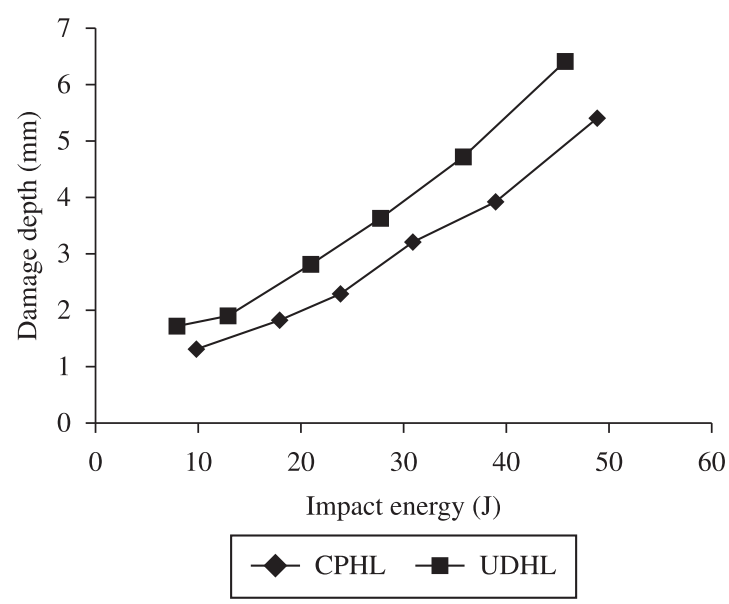

Figure 11. Impact energy vs. Damage depth.

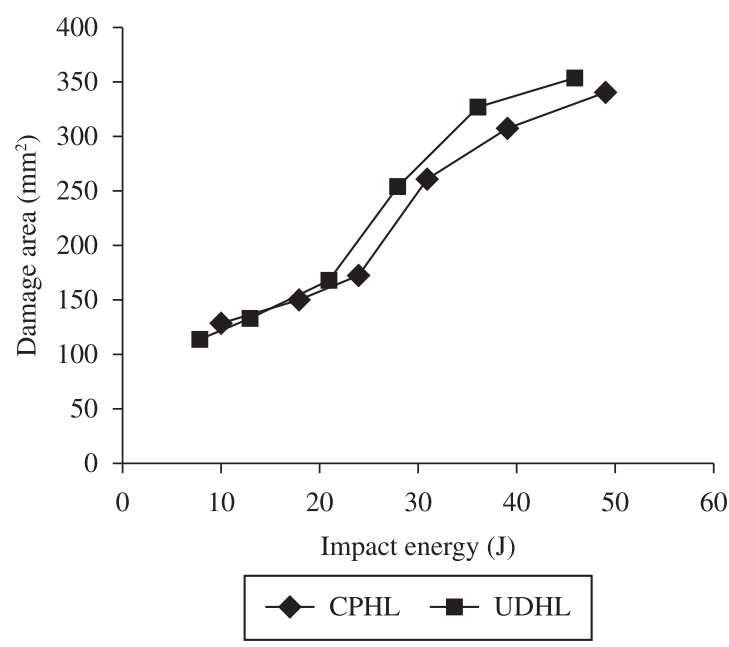

Figure 12. Impact energy vs. Damage area. 
required to create a particular damage is more in the case of CPHL. When compared to aluminium, (Table 3) both UDHL and CPHL have higher specific energy values and hence it is understood that the impact performance of sandwich laminates is better than monolithic aluminium.

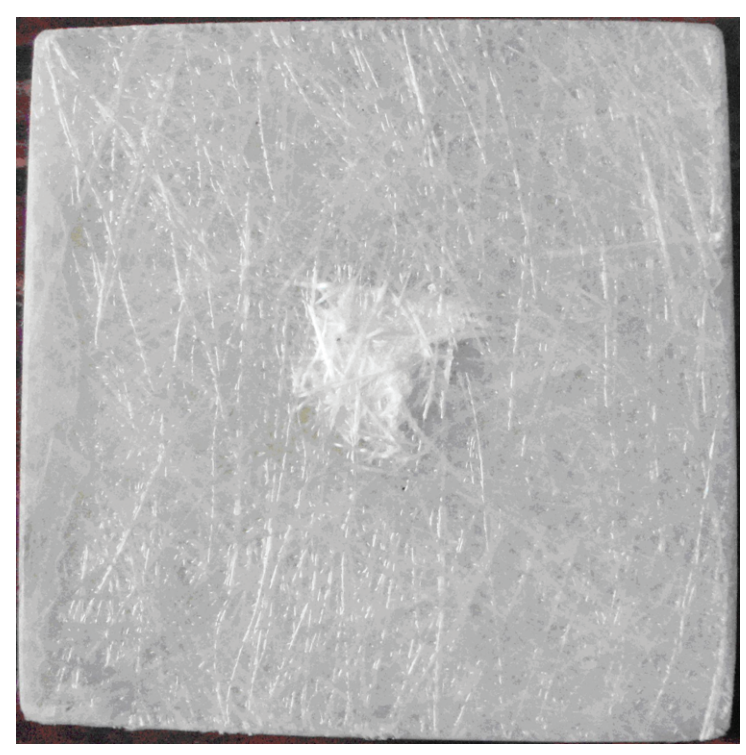

Figure 13. Internal damage zone in GFRP layer after removal of outer aluminium layer at impact energy of $34 \mathrm{~J}$.

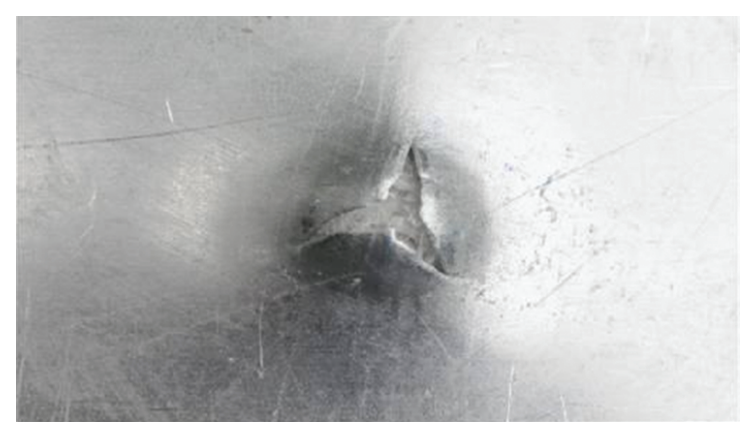

Figure 14. Damage zone in the outer aluminium layer at I.E. of $34 \mathrm{~J}$.

\subsection{Characterization of impact damage}

Figure 11 shows the damage depth as a function of impact energy for UDHL and CPHL having constant fiber and aluminium volume fraction. The damage depth increases with the increase in impact energy. For the same impact energy, it is observed that the damage depth for CPHL is lower than UDHL by about 15 to $18 \%$ again indicating that CPHL has better impact resistance than UDHL.

Figure 12 shows the damage area of the outer aluminum layer for both the UDHL and CPHL having the same $\mathrm{Al}_{\text {tf }}$ of 0.4516 and fiber volume fraction of $35 \%$ for various impact energies. The damage area is defined as the minimum circular area subscribing the damage zone. The damage area increases with increase in the impact energy for both UDHL and CPHL. A sharp increase in the damage area is seen when the impact energy increases from 18 to $26 \mathrm{~J}$. Thereafter the damage area increases continuously with increase in impact energy and finally levels off near the perforation zone. It is also observed that the damage area in the GFRP layer (Figure 13) after chemical removing and careful chipping of the aluminium layer is lower than the damage area in the outer aluminium layer (Figure 14) by about 16 to $24 \%$ for various impact damages/conditions. This might be useful in understanding the extent of damage in the inner GFRP layer indirectly in terms of the damage area of the outer aluminium surface.

\section{Conclusions}

The impact performance of aluminium-glass fiber sandwich panels has been evaluated with respect to change in aluminium thickness fraction, fiber volume fraction and orientation in the layers of GFRP. It is seen that the specific cracking and perforation energy increases with an increase in the fiber volume and aluminium thickness fraction. Sandwich laminates have both these energy values higher than that for monolithic aluminium. The crack initiation is found to be in the fiber direction for both UDHL and CPHL. The internal damage area due to impact in the FRP layer is lower than the damage area in the outer aluminium layer. It is observed that the damage depth and damage area for CPHL is lower than that of UDHL for the same impact energy. Hence the impact performance and the impact resistance of CPHL are better than UDHL.

\section{References}

1. Vogelesang LB and Vlot A. Development of fiber metal laminates for advanced aerospace structures. Journal of Material processing Technology. 2000; 103:1-5. http://dx.doi. org/10.1016/S0924-0136(00)00411-8

2. Asundi A. and Choi AYN. Fiber Metal Laminates: An Advanced Material for Future Aircraft. Journal of Material Processing Technology. 1997; 63:384-394. http://dx.doi. org/10.1016/S0924-0136(96)02652-0

3. Sinke J. Manufacturing of GLARE parts and structures. Applied composite materials. 2003; 10:293-305. http://dx.doi. org/10.1023/A:1025589230710

4. Kawai M, Morishita M, Tomura S and Takumida K. Inelastic behavior and strength of fiber metal hybrid

composite: GLARE. International Journal of Mechanical Sciences. 1998; 40:183-198. http://dx.doi.org/10.1016/S00207403(97)00048-9

5. De Vries TJ and Vlot A. The influence of the constituent properties on the residual strength of Glare. Applied Composite Materials. 2001; 8:263-277. http://dx.doi. org/10.1023/A:1011256202539

6. Borgonge B and Ypma MS. Long term behavior of Glare. Applied Composite Materials. 2003; 10:243-255. http://dx.doi. org/10.1023/A:1025589812963

7. Reyes G and Kang H. Mechanical behavior of lightweight thermoplastic fiber-metal laminates. Journal of Materials 
Processing Technology. 2007; 186:284-290. http://dx.doi. org/10.1016/j.jmatprotec.2006.12.050

8. Wu G. Mechanical behaviour of GLARE laminates for Aircraft Structures. JOM Journal of Minerals, Metals and Material Society. 2005; 57:72-79. http://dx.doi.org/10.1007/s11837005-0067-4

9. Vlot A. Impact loading on Fiber Metal Laminates. International Journal of Impact Engineering. 1996; 18:291-307. http:// dx.doi.org/10.1016/0734-743X(96)89050-6

10. Lawcock GD, Ye L, Mai Y-W and Sun C-T. Effects of Fiber/ Matrix adhesion on carbon-fiber-reinforced metal laminates - II. Impact Behaviour. Composites Science and Technology. 1997; 57:1621-1628. http://dx.doi.org/10.1016/ S0266-3538(97)00094-8

11. Song SH, Byun YS, Ku TW, Song WJ, Kim J and Kang BS. Experimental and Numerical Investigation on Impact performance of Carbon Reinforced Aluminium Laminates. Journal of Material Science and Technology. 2010; 26:327332. http://dx.doi.org/10.1016/S1005-0302(10)60053-9
12. Ghasemi FA, Payeganeh G and Mlaekzadehfard K. A Study on Modelling and Simulation of Dynamic behavior of Fiber Metal Laminares under Low Velocity Impact. In: Proceedings of the Modelling, Identification and Control; 2010; Innsbruck, Austria. IASTED; 2010.

13. Langdon GS and Rowe LA. Blast loading of fibre-metal laminates: preliminary tests. Proceedings of the ICE. Engineering and Computational mechanics. 2011; 164:139146.

14. Mckown S, Cantwell WJ and Jones N. Investigation of Scaling Effects in Fiber-Metal Laminates. Journal of Composite Materials. 2008; 42:865-888. http://dx.doi. org/10.1177/0021998308089750

15. Alderliesten RC, Hagenbeek M, Homan JJ, Hooijmeijer PA, De Vries TJ and Vermeeren CAJR. Fatigue and Damage Tolerance of Glare. Applied Composite Materials. 2003; 10:223-242. http://dx.doi.org/10.1023/A:1025537818644

16. Mallick PK. Fiber reinforced composites. New York: Marcel Dekker, Inc.; 1993. 286 p.

Appendix 1. Abbreviations and nomenclature.

\begin{tabular}{cc}
\hline Abbreviations & Nomenclature \\
\hline GFRP $=$ Glass fiber reinforced plastic & $\mathrm{U}_{\mathrm{f}=\text { Fiber strain energy }}$ \\
$\mathrm{UDHL}=$ Unidirectional Hybrid aluminium glass fiber laminate & $\sigma_{\mathrm{f}}=\begin{array}{c}\text { Longitudinal stress at the outermost layers } \\
\mathrm{CSM}=\text { Chopped strand mat }\end{array}$ \\
$\mathrm{EPHL}=$ Cross-ply Hybrid aluminium glass fiber laminate. & $\mathrm{E}_{\mathrm{f}}=$ Fiber modulus \\
& \begin{tabular}{c}
$\mathrm{Al}_{\mathrm{ff}}=$ Aluminium thickness fraction $_{\mathrm{f}}=$ Fiber volume fraction \\
\hline
\end{tabular} \\
\hline
\end{tabular}

